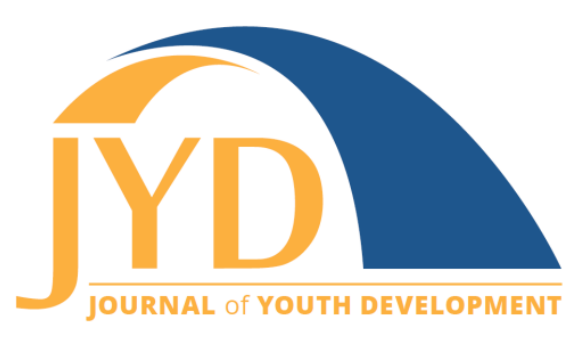

http://jyd. pitt. edu/ | Vol. 13 Issue 3 DOI 10.5195/jyd.2018.615 | ISSN 2325-4017 (online)

\title{
Assessing Multicultural Parenting Values and Practices in Prevention Programs for Latino Youth
}

\author{
Ghaffar Ali Hurtado \\ University of Maryland School of Public Health \\ ahurtado@umd.edu
}

Julie M. Fife

University of Maryland School of Public Health

jfife@umd.edu

\section{Maria V. Svetaz}

Hennepin County Medical Center

maria.svetaz@hcmed.org

Michele L. Allen

University of Minnesota Family Medicine and Community Health

miallen@umn.edu

\section{Abstract}

As communities become increasingly diverse, it is important to consider how cultural navigation interacts with adolescent development. We examined immigrant parenting values and practices to promote healthy development when developing Padres Informados/Jóvenes Preparados (Padres). Three focus groups were conducted with Latino immigrant parents $(\mathrm{n}=27)$. Parents strove to foster a strong Latino identity to protect their children from detrimental preconceived notions about Latinos in the broader American culture. They conveyed a Latino identity by speaking Spanish and teaching the values of respect and familism. Parents expressed tremendous stress in parenting while navigating difficult policies, socioeconomic conditions, and unfamiliar systems. They actively sought practices to protect their children. Parents also held misconceptions about cultural influences and normative development. These findings provided cultural grounding for Padres, which demonstrated success in improving youth-parent relationships. Family-focused programs serving Latino youth need to consider strengthening cultural identity to improve youth-parent relationships and promote optimal development.

Key words: immigrant families, Latino, adolescent health, parenting, prevention

(c) EY New articles in this journal are licensed under a Creative Commons Attribution 4.0 License. This journal is published by the University Library System, University of Pittsburgh and is cosponsored by the University of Pittsburgh Press. The Journal of Youth Development is the official peer-reviewed publication of the National Association of Extension 4-H Agents and the National AfterSchool Association. 


\section{Introduction}

Youth from Latino families are the fastest growing subgroup of youth in the United States (Flores, 2017). By 2025, one in every four youth in the United States will be Latino (Fry \& Passel, 2009; United Nations, 2013). Policy-makers and youth development advocates need to understand how to promote the well-being of this large group of youth who currently report higher rates of teen pregnancy (Centers for Disease Control \& Prevention, 2014), obesity (Ogden, Carroll, Fryar, \& Flegal, 2015), and smoking susceptibility (El-Toukhy, Sabado, \& Choi, 2016) than youth from other ethnic backgrounds. The critical role of the family in promoting adolescent well-being is acknowledged in virtually every psychological and ecological theory of child development. Longitudinal research on adolescent health suggests parents have a larger impact on adolescent behaviors than previously thought (Resnick et al., 1997). Youth in middle school shift their interactions from parents to peers, and while studies have found that peers do influence negative behaviors, it is the youth-parent interaction that is the primary reason "not to use" drugs and other substances (Johnston, O'Malley, \& Bachman, 2001). Literature suggests that many precursors to serious adolescent problems can be reduced or eliminated through intervention to improve parenting and family systems dynamics in adolescence (Kumpfer \& Alvarado, 2003).

Immigration and acculturation challenge family dynamics and shape parenting practices (Martinez, 2006; Shakib et al., 2003). While more than $80 \%$ of Latino youth under the age of 18 years old in the United States were born in the United States (Flores, 2017), most have at least one immigrant parent (Fry \& Passel, 2009). Normative adolescent development involves increased independence and questioning parents' authority and values, which often contributes to family stress (Coleman \& Karraker, 1998). In immigrant families, this stress is compounded by the differential rates at which youth, as compared to their parents, learn to navigate the receiving culture and adolescent culture more broadly (Bacallao \& Smokowski, 2007; Portes \& Rumbaut, 2001; Romero, Martinez, \& Carvajal, 2007). Discrepancies in values, interests, and language make it difficult for youth to maintain close relationships with parents. However, youth who do remain close to their parents and retain their parent's traditional value of "familismo" (Chun \& Akutsu, 2003), while participating in their new culture, are protected against risky behaviors (Romero, Robinson, Haydel, Mendoza, \& Killen, 2004; Smokowski \& Bacallao, 2007). For this reason, exploring how immigrant parents of adolescents promote values through positive parenting practices is an important consideration for Latino youth health promotion programs (Domènech Rodriguez, Donovick, \& Crowley, 2009; Dumka, Roosa, Michaels, \& Suh, 1995). 
This article expands on previous research by exploring how immigrant parents adjust and adapt their values into parenting practices and the challenges they experience conveying these values to their adolescent children. The purpose of this paper is to (a) briefly describe the Padres program and youth outcomes; (b) report findings from focus groups with Latino immigrant parents; (c) describe how those findings were used to develop a family-based prevention program for Latino youth; and (d) provide implications for youth development practice.

\section{Developing Padres Informados/Jóvenes Preparados}

\section{Padres Program Description}

Padres Informados/Jóvenes Preparados (Padres) is a family-skills building program that aims to promote positive parenting and prevent tobacco and other substance use among Latino youth. Padres was created over 9 years of a community-university collaboration (Allen et al., 2013a, Allen et al., 2012) that was formed in response to an identified need for a locally-relevant parenting program to promote positive youth development. The conceptual model for the program (see Figure 1) is based on the ecodevelopmental framework that recognizes the reciprocal relationship between youth and their social ecosystem, including their family relationships and the broader social contexts in which they are situated (Szapocznik \& Coastsworth, 1999). The framework posits that youth development is shaped by the nature of the interactions between youth and their social ecosystem over time (Szapocznik \& Coastsworth, 1999). Padres aimed to improve the quality of these interactions to reduce smoking intention over time.

The program was delivered as a 5-year, multi-site, delayed-control trial. Families were randomly assigned to the intervention ( $n=174$ ) or the delay control group ( $n=178)$. Parent and youth data were collected at baseline (month 0 ), post-test (month 4 ) and follow-up (month 10). Youth data were collected from ( $n=342$ ) Latino ages $10-14$ years. Latino parents were largely born in Mexico (86\%), 53\% reported higher adherence to traditional Latino values, $76 \%$ reported only speaking Spanish in the home, $70 \%$ of parents completed high school, and $80 \%$ earned $\$ 2,000$ or less per month. The average age of youth was 12.3 years, $51 \%$ were female, and $77 \%$ were born in the United States. 
Figure 1: The Padres Informados/Jóvenes Preparados Conceptual Model (Allen et al., 2012)

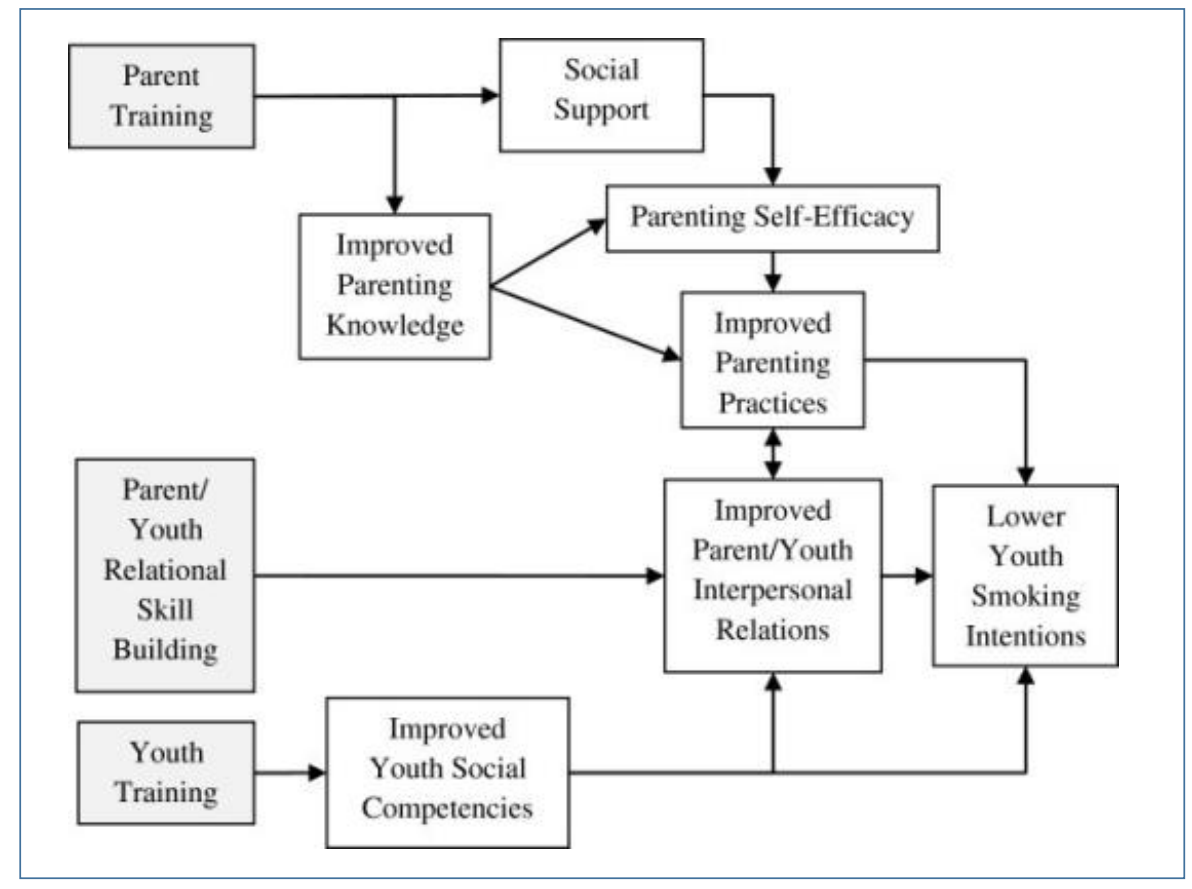

Consistent with previous research, youth reporting more parental attachment were less likely to be susceptible to smoking [AOR $=.510,95 \% \mathrm{CI} . .284-.915]$. At the conclusion of Padres, youth who participated in the program reported more positive parental acceptance $(F(1,311)=$ $4.24, p=.04)$, and improved youth-parent communication $(F(1,309)=5.74, p=.017)$ than youth in the control group. Six months after completing the program, youth who participated in the program continued to report significantly better youth-parent communication $(F(1,276)=$ $4.44, p=.036)$ than youth who did not participate in the program.

The success of Padres can be attributed to the careful selection and development of relevant topics to improve youth-parent relationships in Latino immigrant families, which included parenting styles, living in a multicultural world, adolescent development, family communication and connection, effective discipline, attachment, conflict management and resolution, parental monitoring, and youth refusal skills. To enhance cultural relevance, program developers used a community based participatory research (CBPR) approach (Allen et al., 2013b; Israel, Eng, Schulz, \& Parker, 2005; Wallerstein \& Duran, 2010) that involved conducting focus groups with Latino immigrant parents to explore values that are important to them and the barriers they experience in conveying these values to their adolescent children. 


\section{Methods}

Three 60-minute focus groups were conducted between June and September 2008. Two groups were held at health clinics and one at an elementary public school. These agencies were selected because they primarily served minority populations and were interested in participating. Recruitment strategies included posting flyers at each agency, word of mouth, and presentations at community events. Parents were eligible to participate if they met three criteria: (a) immigrated from Latin America; (b) had an adolescent child age 10 to 18 years; and (c) spoke Spanish.

Two trained Latino graduate students in social science conducted the focus groups using a semi-structured interview guide (see Table 1). All participants provided written informed consent in Spanish and completed a short demographic survey, which included questions about age, gender, years in the United States, country of origin, income, preferred language at home, and number of children. Focus groups were audio recorded, then transcribed verbatim in Spanish. As a token of appreciation for their time, participants received a $\$ 25$ gift certificate. Childcare and light refreshments were provided to overcome barriers to participation. Institutional Review Boards at the University of Minnesota and Hennepin County Medical Center approved this study.

\section{Table 1: Focus Group Questions}

1. What are the most enjoyable things about being the parent of a teenager?

2. What are the key cultural values important to you as a Latino parent of a teenager?

3. How are you using these values in your day-to-day parenting?

4. What are some challenges to using these values?

5. What are the major threats to the health of your teenager?

6. What strategies do you use particularly to prevent smoking?

7. What would you like to learn regarding being a Latino parent of a teenager?

\section{Qualitative Analysis}

Focus groups transcripts were analyzed using a qualitative inductive approach in Spanish (Saldaña, 2012). NVivo software (v. 10) was used to organize the content of transcripts into 


\section{Assessing Multicultural Parenting Values}

nodes/codes, and connect site characteristics to data for comparison across the sites. Four research team members participated in analysis, all of them bilingual to some degree. Researchers examined the transcripts and developed a structure-based code. The team came together frequently to discuss and negotiate the development of new codes and themes as they emerged from the transcripts. After the research team agreed on the major themes found in this study, the transcripts were coded again based on major themes and codes. Demographic information was coded and analyzed using SPSS (v. 20).

\section{Focus Group Participants}

The majority of participants $(n=27)$ were from Mexico $(n=21,78 \%)$. Other regions of origin included Central America $(n=4,15 \%)$, and South America $(n=2,7 \%)$. Eighty-one percent ( $n$ $=22$ ) spoke mostly or only Spanish at home; $22 \%(n=6)$ spoke Spanish and English equally, and only one participant spoke more English than Spanish at home. Most participants were mothers ( $n=23,85 \%)$, who were married or living with a partner $(n=21,78 \%)$. Thirty-three percent $(n=9)$ had a monthly family income of less than $\$ 1000$, about $44 \%(n=12)$ from $\$ 1000$ to $\$ 2000$, and $22 \%(n=6)$ more than $\$ 2000$. The average number of children per household was $3.4(S D=1.3)$. The majority of participants $(80 \%, n=16)$ had elementary and secondary education, but among one group of participants, $(88 \%, n=7)$ had technical college or university training.

\section{Results}

Overall, participants shared positive feelings about parenting an adolescent child. They enjoyed connecting with their youth around music, watching sports, and sharing time together. Across the three focus groups, four key themes related to transnational parenting emerged:

- Traditional parenting values from culture of origin

- Immigrant parenting stressors

- Struggle to maintain transnational Latino cultural identity

- Challenges in parenting while navigating unfamiliar systems

\section{Traditional Parenting Values from Culture of Origin}

Parents described the values of their cultures of origin with pride, and recognized the diversity of their cultural roots within the many traditions of Latin American nations. They recognized that their families are multi-cultural; as one participant stated, "Mother from Mexico and father 
Assessing Multicultural Parenting Values

from Guatemala, but you were born here, and now we all live in the U.S." Participants described specific values from their countries of origin that they wish to convey to their children, including respect/respeto and familism. All groups expressed the importance of respect/respeto, described as respect for the culture of origin, the family, and elders in the community. One parent stated:

Respect for the teacher, for adults, for elders, for grown-ups-it means to talk to them with certain benevolence, respectfully, in an appropriate tone of voice, give them the right of way, offer them the seat, and many things, it implies respect for us, for me.

Parents also underscored the importance of familism, which emphasizes warm, close and supportive family relationships (Campos et al., 2008). Parents taught familism by explicitly expecting their children to be involved in family matters, regardless of whether the issue was related to the transnational family or the family based in the United States. They also expected their children to continue honoring the hierarchy of all the extended family, regardless of its transnational origin and nature. One mother described:

Since my mother lives with me, I always tell my son, "Arriving from school, greet your grandmother. If you are going out let your grandmother know. Always show respect. If she says you're not going out, you're not going. You have to respect your grandmother, if your mother is not around, your grandmother is in charge."

\section{Immigrant Parenting Stressors}

Parents described multiple stressors of being an immigrant. They explained that being an immigrant parent of an adolescent is "double work" compared to what a non-immigrant parent would face. One stressor described was "mixed status families," when one or more family members' status is not documented. Within these families it is typical that parents and perhaps older children are not documented, while younger children who are born in the United States. are U.S. citizens. Parents explained how this creates a power differential that undermines their parental authority. One parent stated:

I have a 12-years-old nephew. His mom punished him [for something he did], and the boy threatened her "I'm going to call the [police] station so they can take you away." I was like, what? 
She started to cry saying, "Look, I can't say anything because the authorities will take me away to the police."

Participants also described stress that stemmed from their socioeconomic circumstances in terms of the need to work multiple jobs. Two fathers described their frustration at the economic realities and its impact on their ability to spend time with their children.

I will tell you one thing, in this county, including all of us here in this room, we know that nothing is free, so it's important to work a lot. The kids are in front of the television a lot or in school the majority of time, so if $90 \%$ of the time young people are not under parental control, does that let me be an example?

In my country, all of us eat together. Here not. Here the children are eating a sandwich while the lady is preparing to go to work.

Parents worried about their youths' safety in dangerous neighborhoods. They were concerned about their children being victimized or becoming involved with gangs, and adapted parenting practices to protect their children even when they were not physically present. One mother explained:

They'll call me when I'm at work asking, "Mom, may I have permission to go to the store?" Because I have taught them to be very careful when they go out. There's so much insecurity, so many gangsters . . . and when they get involved in gangs, all the bad that could happen to them and to others.

\section{Maintaining a Transnational Latino Cultural Identity.}

Participants expressed a strong preference for their adolescent to maintain an exclusively Latino cultural identity that is intimately tied to their transnational family and values structure. Parents defined a Latino cultural identity as continuing to speak Spanish, understanding the values held by their transnational families, and maintaining a close connection with family in their country of origin. Cultural identity was seen as a mechanism for ensuring adherence to parents' values; however, they also recognized that a broader cultural orientation would protect their children against assumptions made about them by the outside world. As a rationale for why her daughter should identify as Mexican, one mother explained that her daughter would generally not be perceived as "American" due to her physical appearance. 
Assessing Multicultural Parenting Values

"Mommy, those of us who were born here, are we Mexicans or Americans?" I said no, you are Mexican. Because we are [all] Mexicans . . . Now, thank God you all were born in one country in which you can enter and leave. You have different nationality but that does not mean that you are American-look at the color of your skin, and color of your hair.

Parents believed that their children would be more confident if they understood the cultural values of their home countries and valued family traditions. One parent expressed, "It's important that children know their origin, where their parents come from. Teach them the ways of our traditions, so that they understand and feel confident in who they are."

Parents described the importance of conveying Latino cultural identity through speaking Spanish. Parents recognized the benefits of having both English and Spanish language abilities to navigate multiple worlds, but emphasized the necessity for Spanish in maintaining their cultural identity.

To speak Spanish correctly, to know how to write it, to know how to read it and properly pronounce it. Because despite being raised here, despite living in an Anglo community, they need to know their origins and do things properly.

Parents identified libertinaje (i.e., debauchery, liberal behavioral norms) as the most significant challenge to their parental values in how U.S. norms influenced their children's attitudes and expectations in areas such as dating, materialism, and style of dress.

The cultural values for our children begin at home. When they go to school and observe other children with their pants falling down, they request to "buy them those pants," "buy a similar T-shirt," and I say no. Just because you are living in United States, it does not mean you will dress like them. [I asked them] how many times have you seen your father dress like that? Our cultures are different in the way we dress, in the way we talk, in the way you express yourself to others with respect... regardless who they are. 


\section{Challenges in Parenting while Navigating Unfamiliar Systems.}

Parents wrestled with navigating the education, police, and health care systems that their adolescents had largely mastered. One parent described the difficulty of not having as much information about the school system as her child, she said:

Recently I learned my son was escaping from [skipping] school. I take him every morning, and I believed I was leaving him to enter in one door and he was leaving through another. I went to connect to the school. I asked, "How it is possible that my son is absent so many times and I was not aware of it?" Well there is a system that calls home, and I [had previously] asked my son "There are some messages from your school; they said you are not there." [He replied] "No mom, it is because I changed a class and the system surely is not up to date yet." Well, he kept me blind.

Parents described stories of persevering within these unfamiliar systems in order to support their children. One mother shared:

A policeman took her away and told me that, well, she was found with marijuana at school. My world fell apart... there were days truly I almost threw in the towel . . . it was a hard situation that I was going through with my daughter, but I tried to search for help. I never gave up, sometimes my husband said to me "Let her do what she wants, she wants that life, she wants to have, well, her own decisions."

\section{Discussion}

To address the parenting needs of Latino immigrant families, the development stage of Padres involved conducting focus groups to identify immigrant Latino parents' perspectives on parenting values, how they incorporated values into their parenting practices, and the challenges they experienced conveying these values to their adolescent children. Parents expressed a desire to foster a strong Latino cultural identity by maintaining familial relations and reinforcing cultural values from their countries of origin for their children. Parents readily recognized that the broader American culture may hold preconceived notions of their children 
Assessing Multicultural Parenting Values

that are likely to be detrimental, and as a result, emphasized the protective benefits of grounding their youths' identity in their culture of origin.

Parents actively sought parenting practices to protect and nurture their children within unfamiliar cultures and systems. Consistent with prior research (White, Roosa, Weaver, \& Nair, 2009), parents identified protective parenting behaviors (e.g., holding family meals and investing time in their children), but described how immigration policies, socioeconomic challenges, and biases within the wider community were barriers to implementing these practices. Though these parents expressed resiliency and creativity in adapting their parenting to changing circumstances, they expressed a tremendous amount of stress.

Some stress may originate from misperceptions that these parents held in regards to influences on their children. In describing cultural threats to their children's well-being, parents identified a perception about the broader values of parents in the United States that are likely at the extreme end of permissive parenting practices, suggesting a potential misreading of the attitudes of parents in the host culture. Furthermore, parents linked new ways of dressing and behavior in their children exclusively to the more permissive host culture, with little recognition of the developmental transition of adolescence. Parents did not, for instance, recognize that these behaviors might be expressions of typical adolescent development.

\section{Implications for Practice}

Four key points from the focus groups provided cultural grounding for the Padres program. These key points are important considerations for practitioners serving immigrant Latino families with adolescents. These key points are:

1. A need to normalize the notion that immigrant families with adolescents are living in multiple worlds. To address this need, Padres used the acculturation and adaptation model (Berry, 1997). Parents and youth were given a chart with four quadrants labeled Integration, Assimilation, Separation, and Marginalization. Each concept was defined and discussed. Using two different colored dots, youth and parents (separately) placed themselves and their parent or child in one of the four quadrants. This activity generated meaningful discussion, helping create awareness of the individual and family cultural navigation journey.

2. A need to frame families in transition both in terms of cultural navigation and adolescent development, with the acknowledgement that transitions involve stress. Padres emphasized strategies that contribute to healthy transitions. Parents 
explored their own experiences as adolescents as a way to build empathy for their children's experiences and reflected on experiences with their own parents that were either supportive or negative.

3. A need to provide parental education on adolescent development and give examples of normative adolescent behavior. Padres explicitly linked developmental changes in adolescence with cultural values of respeto and familism. Padres worked with parents to identify how they can both preserve those values and support their children to achieve adolescent developmental milestones.

4. A need to underscore that parents' instincts for transmitting transnational cultural values are appropriate and desirable and will be protective for their children. To meet this need, Padres asked parents to troubleshoot ways to make those traditional parenting values easier to apply in ways that benefit youth. Parents described a fun family event they participated in while growing up, what they learned from it or what it meant to them, and generated ways they can do a similar activity with their child.

\section{Limitations}

This study was implemented in a Midwestern urban area that is described as a non-traditional Latino immigrant settlement. The lived experiences of parents and youth who participated in the Padres program may differ from the experiences of Latino families living in other parts the country. While these findings may not be generalizable to all immigrant communities in the United States, this research provides valuable insight about the experiences of immigrant families living in areas with limited services to support Latino parents and youth. Future research should identify and evaluate specific strategies to support parents in managing cultural and developmental transitions, and subsequent adolescent development outcomes.

\section{Acknowledgments}

Research reported in this publication was supported by the National Cancer Institute of the National Institutes of Health under Award Number U54CA153603. The content is solely the responsibility of the authors and does not necessarily represent the official views of the National Institutes of Health. 


\section{References}

Allen, M. L., Svetaz, M. V., Hurtado, G. A., Linares, R., Garcia-Huidobro, D., \& Hurtado, M. (2013a). The developmental stages of a community-university partnership: The experience of Padres Informados/Jovenes Preparados. Progress in Community Health Partnerships: Research, Education, and Action, 73), 271-279.

Allen, M. L., Hurtado, G. A., Yon, K. J., Okuyemi, K. S., Davey, C. S., Marczak, M. S., . . Svetaz, V. M. (2013b). Feasibility of a parenting program to prevent substance use among Latino youth: A community-based participatory research study. Health Promotion, 274), 240-244.

Allen, M. L., Garcia-Huidobro, D., Hurtado, G. A., Allen, R., Davey, C. S., Forster, J. L., . . Reynoso, U. (2012). Immigrant family skills-building to prevent tobacco use in Latino youth: Study protocol for a community-based participatory randomized controlled trial. Trials, 13(1), 242.

Bacallao, M. L., \& Smokowski, P. R. (2007). The costs of getting ahead: Mexican family system changes after immigration. Family Relations, 56(1), 52-66.

Berry, J. W. (1997). Immigration, acculturation, and adaptation. Applied psychology, 46(1), 5-34.

Campos, B., Schetter, C. D., Abdou, C. M., Hobel, C., Glynn, L., Sandman, C. (2008). Familialism, social support, and stress: Positive implications for pregnant Latinas. Cultural Diversity and Ethnic Minority Psychology, 14(2), 155-162.

Centers for Disease Control and Prevention. (2014). Quickstats: Birth rates for females aged15-19 years, by race/ethnicity-National Vital Statistics System. Morbidity and Mortality Weekly Report. Retrieved from https://www.cdc.gov/mmwr/preview/mmwrhtml/mm6328a6.htm?s_cid=mm6328a6_e

Coleman, P. K., \& Karraker, K. H. (1998). Self-efficacy and parenting quality: Findings and future applications. Developmental Review, 18(1), 47-85. doi: 10.1006/drev.1997.0448

Chun, K. M., \& Akutsu, P. D. (2003). Acculturation among ethnic minority families. In K. M. Chun, P. Balls Organista, \& G. Marín (Eds.), Acculturation: Advances in theory, measurement, and applied research (pp. 95-119). Washington, DC, US: American Psychological Association. doi: $10.1037 / 10472-008$

Domènech Rodriguez, M. M., Donovick, M. R., \& Crowley, S. L. (2009). Parenting styles in a cultural context: Observations of "protective parenting" in first-generation Latinos. Family Process, 48(2), 195-210.

Dumka, L. E., Roosa, M. W., Michaels, M. L., \& Suh, K. W. (1995). Using research and theory to develop prevention programs for high risk families. Family Relations, 44(1), 78-86.

El-Toukhy, S., Sabado, M., \&Choi, K. (2016). Trends in susceptibility to smoking by race andethnicity. Pediatrics, 138(5), e20161254. 
Journal of Youth Development | http://jyd.pitt.edu/ | Vol. 13 Issue 3 DOI 10.5195/jyd.2018.615

Assessing Multicultural Parenting Values

Flores, A. (2017). How the U.S. Hispanic Population is Changing. Retrieved from Pew Research Center website: http://www.pewresearch.org/fact-tank/2017/09/18/how-the-u-s-hispanic-population-ischanging/

Fry, R., \& Passel, J. S. (2009). Latino children: A majority are US-born offspring of immigrants. Retrieved from Pew Research Center Hispanic Trends website: http://assets.pewresearch.org/wpcontent/uploads/sites/7/reports/110.pdf

Israel, B. A., Eng, E., Schulz, A., \& Parker, E. A. (2005). Introduction to methods for CBPR for health: Methods in community-based participatory research for health. San Fransisco, CA: Jossey-Bass.

Johnston, L. D., O'Malley, P. M., \& Bachman, J. G. (2001). The monitoring the future national survey results on adolescent drug use: Overview of key findings, 2000. Rockville, MD: National Institute on Drug Abuse.

Kumpfer, K. L., \& Alvarado, R. (2003). Family-strengthening approaches for the prevention of youth problem behaviors. American Psychologist, 56(6-7), 457-465.Martinez, C. R. (2006). Effects of differential family acculturation on Latino adolescent substance use. Family Relations, 55(3), 306317.

Martinez, C. R. (2006). Effects of differential family acculturation on Latino adolescent substance use. Family Relations, 55(3), 306-317.

Ogden, C. L., Carroll, M. D., Fryar, C. D., \& Flegal, K. M. (2015). Prevalence of obesity among adults and youth: United States 2011-2014 [NCHS data brief, no 219]. Hyattsville, MD: National Center for Health Statistics.

Portes, A., \& Rumbaut, R. G. ( 2001). Legacies: The story of the immigrant second generation. Berkeley: University of California Press.

Resnick, M. D., Bearman, P. S., Blum, R. W., Bauman, K. E., Harris, K. M., Jones, J... Udry, J. R. (1997). Protecting adolescents from harm. Findings from the National Longitudinal Study on Adolescent Health. Journal of the American Medical Association, 278(10), 823-832.

Romero, A., Robinson, T., Haydel, K. F., Mendoza, F., \& Killen, J. (2004). Associations among familism, language preference, and education in Mexican-American mothers and their children. Journal of Developmental and Behavioral Pediatrics, 25(1), 34-40. doi:10.1097/00004703-200402000-00006

Romero, A. J., Martinez, D., \& Carvajal, S. C. (2007). Bicultural stress and adolescent risk behaviors in a community sample of Latinos and non-Latino European Americans. Ethnicity and Health, 12(5), 443-463.

Saldaña, J. (2012). The coding manual for qualitative researchers. Thousand Oaks, CA: Sage.

Shakib, S., Mouttapa, M., Johnson, C. A., Ritt-Olson, A., Trimidad, D. R., Gallaher, P. E., \& Unger, J. B. (2003). Ethnic variation in parenting characteristics and adolescent smoking. Journal of Adolescent Health, 33(2), 88-97. 
Journal of Youth Development | http://jyd.pitt.edu/ | Vol. 13 Issue 3 DOI 10.5195/jyd.2018.615

Assessing Multicultural Parenting Values

Smokowski, P. R., \& Bacallao, M. L. (2007). Acculturation, internalizing mental health symptoms, and self-esteem: Cultural experiences of Latino adolescents in North Carolina. Child Psychiatry \& Human Development, 37(3), 273-292.

Szapocznik, J., \& Coatsworth, J. D. (1999). An ecodevelopmental framework for organizing theinfluences on drug abuse: A developmental model of risk and protection. In M. D. Glantz \& C.R. Hartel (Eds.), Drug abuse: Origins \& interventions (pp. 331-366). Washington, DC:American Psychological Association.

United Nations, Department of Economic \& Social Affairs. (2013). The number of international migrants worldwide reaches 232 million. Retrieved from http://esa.un.org/unmigration/documents/The_number_of_international_migrants.pdf

Wallerstein, N., \& Duran, B. (2010). Community-based participatory research contributions to intervention research: The intersection of science and practice to improve health equity. American Journal of Public Health, 100(S1), S40-S46.

White, R. M. B., Roosa, M. W., Weaver, S. R., \& Nair, R. L. (2009). Cultural and contextual influences on parenting in Mexican American families. Journal of Marriage and Family, 71(1), 61-79. doi: 10.1111/j.1741-3737.2008.00580.x 